\title{
Employees' perceptions of human resource management practices and employee outcomes
}

Shaoheng Li

Christopher J. Rees

Mohamed Branine

This is the Author Accepted Manuscript. The final published version is available at Emerald via doi: https://doi.org/10.1108/ER-01-2019-0065 


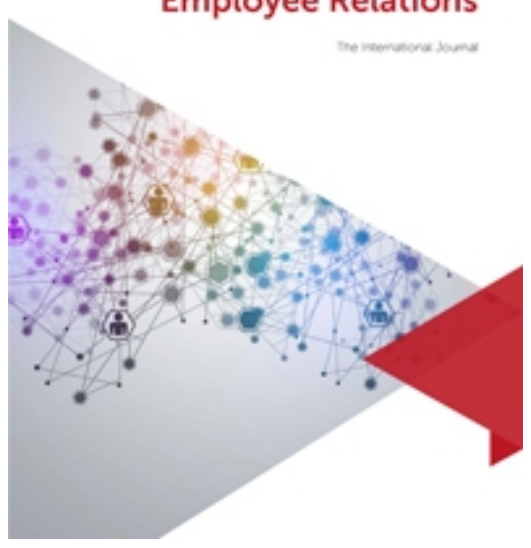

Employees' Perceptions of Human Resource Management Practices and Employee Outcomes: Empirical Evidence from Small and Medium-Sized Enterprises in China

\begin{tabular}{|r|l|}
\hline Journal: & Employee Relations \\
\hline Manuscript ID & ER-01-2019-0065.R1 \\
\hline Manuscript Type: & Research Paper \\
\hline Keywords: & Employee Perception, HRM Practices, SMEs, Motivation, Turnover \\
\hline \multicolumn{2}{|l}{} \\
\hline
\end{tabular}




\title{
Employees' Perceptions of Human Resource Management Practices and Employee Outcomes: Empirical Evidence from the Small and Medium-Sized Enterprises Sector in Mainland China
}

\begin{abstract}
Purpose - The purpose of this paper is to examine the relationship between employees' perceptions of HRM practices and two outcomes, namely, employee commitment and turnover intention, in small and medium-sized enterprises (SMEs) in mainland China.

Design/methodology/approach - This paper adopts a quantitative approach based on a sample of 227 employees working in 24 SMEs in eastern and western China. Findings - Employees' perceptions of HRM practices such as training and development, reward management, and performance management, are significant predictors of employee commitment. A negative direct relationship is found between employees' perceptions about the use of HRM practices and turnover intentions.

Research limitations/implications - Although data were collected from two representative provinces of eastern and western China, the size of the sample may limit the generalisability of the findings to the wider region.

Practical implications - The relationship between employees' perceptions of HRM practices and employee outcomes in Chinese SMEs provides an effective way for SME owners and HR practitioners to generate desirable employee attitudes and behaviours, which, ultimately contribute to improving organisational performance.

Originality/value - This is an original paper which makes a contribution by helping to address the dearth of studies which have explored aspects of the effectiveness of HRM in SMEs in China. In contrast to the majority of Chinafocused studies on this topic, it highlights HRM outcomes at the individual level rather than the organisational level. Further, the study involves SMEs in western China which is an under-explored region.

Keywords - commitment, HRM practices, perceptions, SMEs, turnover

Paper type Research paper
\end{abstract}

It has been well documented that small and medium enterprises (SMEs) make a considerable contribution to economic development, poverty reduction and job creation, especially in developing countries (Cooke, 2012; Maksimov et al., 2017). The prominent role of SMEs in the national economy and social stability has also been recognised in China. Further, there is a body of HRM-oriented research which is focused on the SME sector (Bai et al., 2017; Cegarra-Leiva et al., 2012; Cunningham, 2010; Qiao et al., 2015; 
Richbell et al., 2010; Zheng et al., 2006). It is apparent from this literature that HRM problems act as key constraints that hinder the development and profitability of organisations in the SME sector with debates arising among HR practitioners, SME owners, scholars and even policy makers about the meaning and promotion of effective HRM in the sector (Cooke, 2012; Cunningham and Rowley, 2008; Harney and Dundon, 2006; Lai et al., 2017). Yet, although HRM practices and performance linkages have been widely examined in HRM literature, most studies are western-based, and/or focused on organisational performance, multinational corporations (MNCs) and the public sector (Gould-Williams and Mohamed, 2010; Wright et al., 2005). More, specifically, little is known about the relationship between HRM practices and employee outcomes at the individual level in the SME sector in China. In addition, there is some evidence that findings from empirical studies in Chinese organisational contexts are influenced by the contexts in question (Nazir et al., 2016; Shen and Leggett, 2014; Hu et al., 2018) which further necessitates the need for research which is focused directly upon the SME sector in China.

The SME sector in China has undergone a unique and somewhat tortuous development path over the past six decades (Warner, 2009; Wang, 2016). This path commenced with the phase of early existence, then near disappearance, followed by primary growth, and currently to rapid expansion, promotion and upgrade. In essence, along with the raised status of the private economy in the national economic structure and a series of profound reforms across the nation, private enterprises (PEs), especially in the form of SMEs, have gradually gained legitimacy, recognition and encouragement. Evidence of this recognition can be seen from amendments to the Constitution during the period of 1988 to 2004, in which the status of the privately-owned enterprises was both acknowledged and raised; rather than privately-owned enterprises representing a mere 
supplement to the activities of state-owned enterprises, the development of PEs is now encouraged, supported and guided by the State (PRC, 2004). Nevertheless, the ideologically-driven discrimination against PEs which initially existed following the formation of the PRC, coupled with the relatively short period of time during which their development has been legitimised by the Chinese State, privately-owned SMEs tend to be more vulnerable and have less access to support than other forms of enterprises, such as state-owned enterprises, collective-owned enterprises and large-sized MNCs.

The definition of an SME has been updated four times since the PRC was founded in 1949 (Cunningham, 2011). The latest quantitative criteria were published in 'Provisions on the Standards for SMEs' in 2011 (PRC, 2011). Although the definitions by the number of employees largely vary across sectors, we defined an SME as an enterprise with fewer than 300 employees; this cut-off point is applicable to the most sectors listed in the Provisions. Considering the facts that the majority of SMEs are private enterprises and the degree of the development of HRM (Cunningham, 2011), this paper focuses on urban-based privately-owned SMEs.

Given the need to facilitate the development of SMEs from an HRM perspective and the lack of research in this area, the main aim of this study is to investigate the relationship between employees' perceptions of HRM practices and employee outcomes in SMEs in mainland China.

\section{HRM Practices and Outcomes in SMEs}

The potential relationship between HRM and its outcomes has been explicitly recognised in seminal HRM theories such as the Harvard Framework (Beer et al., 1984) and the resource-based view (RBV) of the firm (Wright et al., 1994). For example, the Harvard Framework (Beer et al., 1984, p.16) illustrates the complex connection between 
'stakeholder interests', 'situational factors', 'HRM policy choices', 'HR outcomes' and 'long-term consequences' and has provided a fundamental reference point in HRM not only for theoretical development, but also for international and comparative studies (see Marchington, 2015). Similarly, while recognising various criticisms that have been levelled against it (see Boxall and Purcell, 2011; Saridakis et al., 2017), RBV has offered a particularly helpful contribution to HRM empirical research as it justifies the strategic value of HRM to an organisation by highlighting the role of human resources in achieving sustainable competitive advantage and improving organisational performance (Hailey et al., 2005). As such, HRM theories such as the Harvard Framework and the RBV provide a solid theoretically-based rationale for analysing the relationship between HRM determinants, choices and outcomes especially when this analysis is focused on geographical contexts and sectors such as SMEs in China which have yet to receive widespread attention in HRM literature.

It is noted that the linkage between HRM practices and performance in various types of firms has been widely studied (Krishnan and Scullion, 2017; Lee et al., 2010; Zheng et al., 2009). Specifically, much attention has been paid to performance at the organisational level as measured by indicators such as productivity, turnover, profitability, sales growth, return on investment, firm innovation (Ceylan, 2013; Chowhan, 2016; Wright et al., 2005; Zheng et al., 2009). Employee outcomes focusing on individual attitudes and behaviours play a mediating role between HR-performance linkage, which is theoretically supported by the Harvard Framework and which has been empirically examined by previous literature. For example, Katou and Budhwar's (2007) Greek-based research $(\mathrm{N}=600)$ found a positive relationship between staffing, development, compensation, involvement and job design and firm performance, mediating by staff skills, attitudes and behaviours. A recent study consisting of 448 
privately-owned SMEs in the UK found the positive relationship between formal HRM practices and financial performance was moderated by employee satisfaction, but not by organisational commitment (Lai et al., 2017). In China, based on the analysis of 74 SMEs in ten big cities, Zheng et al. $(2006,2009)$ found that the adoption of a set of high performance and innovative HRM practices predicted enhanced financial and market performance through improved HRM outcomes.

\section{Employees' perceptions of HRM Practices}

The relative importance of contextualised research which explores employees' perceptions of HRM practices is emphasised and succinctly summarised by Storey et al. (2010: 305) when they draw attention, as follows, to the distinction between intended and actual HRM practices: "Intended practices may or may not lead to actual practices; the effects of these actual practices are mediated by employees' perceptions and perceptions shape employees' attitudinal and behavioural responses". Similarly, when exploring links between HRM system strength and employees' affective outcomes, Cafferkey et al. (2018: online, p.1) highlight the importance of research that: "brings workers back into the debate by exploring employees' opinions of, and subsequent reaction to, HRM initiatives". Cafferkey et al. (ibid) contend that employees view, in an attributional manner, HRM practices as indicators of organisational support; thus employees' perceptions of HRM practices may influence the human relations climate and, as a result lead to employee outcome behaviours.

This attributional approach complements earlier work on HRM system strength (Bowen and Ostroff, 2004: 207) which recognised HRM practices as "communications from the employer to the employee". Bowen and Ostroff conclude, however, that research on HRM practices has: "typically relied on reports from a higher-level manager or HR 
executive... we suggest that a better alternative is to assess these characteristics of the HRM system from employees themselves" (ibid: 216). In relation to the measurement of the HRM system's visibility and consistency, Bowen and Ostroff(2004) point to the value of perception-oriented research which involves employees indicating the extent to which they feel HRM practices are utilised in the firm, as well as the extent to which employees feel they have personally experienced these practices.

Yet, despite the recognised association between employees' perceptions of HRM practices and their behavioural responses to these practices (Nishii et al.; 2008), SMEfocused research on this issue in China remains scarce in terms of scope and depth (Cooke, 2009). Thus, a body of emerging research has focused on, for example, the nature and the development of HRM in SMEs, HRM practices adopted in SMEs, the comparison of HRM practices between large/western firms and SMEs, factors in shaping HRM choices (Cooke, 2005; Cunningham, 2010; Cunningham and Rowley, 2008, 2010). Extremely limited attention has been paid, however, on examining employees' perceptions of HRM practices, especially with a focus on the individual level outcomes with the notable exception of the work of Zheng et al. $(2006,2009)$ though their research samples are not exclusive to privately-owned SMEs in China.

We respond to these gaps in literature by exploring employees' perceptions of HRM practices with reference to employee outcomes in the SME sector in China. For the purpose of this study, two specific employee outcomes have been placed under scrutiny, that is, organisational commitment and turnover intention. While recognising that a relationship may, in time, be shown to exist between these two outcomes (see Dhiman and Mohanty, 2010; Juhdi et al., 2013), both of these outcomes have, on the basis of existing literature, the potential to reflect employees' attitudes and behaviours in organisations at the individual level. 


\section{Organisational Commitment (OC)}

From a theoretical perspective, organisational commitment represents a multidimensional concept intended to capture complicated human psychological and behavioural response in the workplace (Meyer and Allen, 1991). For example, the threecomponent model developed by Meyer and Allen (1991) proposes that OC has three distinct components, that is, affective commitment (AC), continuance commitment (CC) and normative commitment (NC). The model has been widely adopted in different cultural settings despite the inconsistent reliability of results obtained when assessing the three components (Eisinga et al., 2010; Kehoe and Wright, 2013). In addition, the literature has suggested that OC is closely associated with other predictors, such as absenteeism, job satisfaction, turnover and so forth (Eisinga et al., 2010; Lambert and Hogan, 2009; Meyer and Allen, 1991). More importantly, considering SMEs' vulnerable nature and limited resources, OC appears to have potentially important implications to SMEs in terms of strengthening the bond between organisations and individuals.

From an empirical perspective, although OC has been extensively studied, relatively few research studies have been conducted involving SMEs (Saridakis et al., 2013; Zheng et al., 2009). It is noted that SME-focused studies have sought to shed light on the relationships that exist between OC and variables such as career development and performance appraisal (Meyer and Smith, 2000), autonomy and supervision (Newman and Sheikh, 2012); and participation in training (Pajo et al., 2010). For example, the findings of one UK-based study indicate that the adoption of formal HRM practices increases OC in SMEs with low employee satisfaction (Saridakis et al., 2013). More specifically, however, the nature of the relationship that may exist between OC and HRM practices in SMEs, particularly in China, remains vague and requires further exploration. 
Thus, it is rational and necessary to employ OC as one of the focused employee outcomes in this paper.

Based on the preceding discussion of the Harvard Framework suggesting the link between HRM practices and their outcomes, and prior empirical evidence, three research hypotheses in relation to $\mathrm{OC}$ in the SME sector in China have been formulated and are presented below.

Hypothesis 1a: The greater use of HRM practices will lead to higher affective commitment.

Hypothesis 1b: The greater use of HRM practices will lead to higher continuance commitment.

Hypothesis 1c: The greater use of HRM practices will lead to higher normative commitment.

\section{Turnover Intention (TI)}

Existent literature has documented that high level of turnover can increase HR costs, decrease productivity, lose experienced employees and their established business network, and lower employee morale (Kuean et al., 2010; Lambert and Hogan, 2009). Given the lower levels of job security, lack of training and lack of growth opportunities, and less comprehensive compensation package compared with large scale enterprises, there is higher level of employee voluntary turnover in the SME sector in China; in turn, this turnover acts to constrain the growth of SMEs (Warner, 2011). The widespread labour shortage and imbalanced structure of the workforce in the Chinese labour market serve to worsen further the situation (Cooke, 2012; Cunningham and Rowley, 2008). Thus, it is necessary to explore further the issue of turnover in this context. 
Turnover intention (TI) is widely considered to be a reliable and accurate predictor of voluntary turnover behaviour (Kim, 2014; Sun and Wang, 2017). As such, the turnover process can be composed of four levels, beginning with 'thinking of quitting', followed by an 'intention to search', an 'intention to quit / stay' and eventually leading to the decision to 'quit / stay' (Mobley et al., 1978, p.410). Empirically, substantive evidence exists to explain the relationship between HRM practices and turnover at the organisational level (Eriksson et al., 2014). However, TI at the individual level remains relatively underexplored particularly within the SME sector. What evidence that has emerged across a range of countries and sectors, tends to suggest that there is a direct or indirect negative relationship between TI and HRM practices (see Cegarra-Leiva et al., 2012; Dhiman and Mohanty, 2010; Fabi et al., 2015; Juhdi et al., 2013). Inconsistent results are found in the SME sector. A study consisting of 232 family-owned SMEs in Austria and Hungary concluded that the strengthening of family status and influence, when coupled with the adoption of high performance work practices, exerts a positive influence on employee retention (Pittino et al., 2016). Similarly, Cegarra-Leiva et al.'s (2012) work with a sample of 110 SMEs suggests that the work life balance supportive culture negatively predicts TI rather than the actual practices. Pajo et al. (2010) concluded that participation in more formal T\&D activities tends to lower employee TI. However, with the notable exceptions of the above studies, there is a paucity of evidence relating to HRM and TI in the SME sector, especially in SMEs in China. Therefore, the research hypothesis in relation to TI has been formulated as below.

Hypothesis 2: The greater use of HRM practices will lead to lower turnover intention. 


\section{Methodology}

\section{Sample}

Given that China is a relationship-based society, a non-probability sampling method, snowball sampling, was adopted to help to overcome the documented difficulties involved in identifying, gaining access to, and sampling SMEs in China. This method has been widely used in HRM research in Chinese contexts (Cai et al., 2011; Cunningham, 2010; Kim and Gao, 2010; Zheng et al., 2006). We sampled in two provinces, Jiangsu and Shaanxi. Jiangsu is located at eastern coastline, which is the centre of the Yangtze River delta. It is one of the most economically developed regions in China. Shaanxi is in western inland China. It is the centre of the five north-western provinces, which is typical in the north-western region. These two provinces are representative of eastern coastal and western inland China.

343 questionnaires were distributed to employees working at various levels in 24 privately-owned SMEs. 284 questionnaires were returned and 227 were valid, representing a response rate of $66 \%$. On average, nine valid questionnaires were collected per firm $(S D=4.4)$. The questionnaires were delivered and collected in groups either by the researchers or by the HR managers while the researchers were present at the firms. Envelopes were provided to keep the responses anonymous. 58.6\% of the respondents were between 21-30 years old, followed by the group of 31-40 (32.2\%). The average tenure of the respondents was 31.3 months $(S D=30.3) .78 .9 \%$ of the respondents had a professional college degree or a higher qualification. 12 of the 24 SMEs were located in Shaanxi and the other half were in Jiangsu Province; $38 \%$ of them were in the manufacturing sector and $62 \%$ were in the service sector. The longevity of the SMEs ranged from three to 18 years with a mean of 10.2 years $(S D=4.7)$. 


\section{Measures}

In this study, we adopted the approach of Cafferkey et. al. (2018: online p.17) which, in a Malaysian context, placed: "the employee and their perceptions of HRM as the basis of understanding" in order to overcome: "bias in terms of traditional/orthodox Westernized research paradigms through privileging organizational and managerial vested interests over other stakeholder groups". Employees' perceptions relating to the use of HRM practices were measured by 39 items (Cronbach's $\alpha=0.95$ ). The respondents were asked about the use of particular HRM practice in their organisations. These items were designed using HRM literature with a focus on SMEs (Cunningham, 2010; Kotey and Slade, 2005; Zheng et al., 2006). They reflect key aspects of HRM practices including recruitment and selection, $T \& D$, performance management, reward management and $\mathrm{HR}$ planning, such as the presence of written HRM documents and the use of forms, selection methods, induction programmes, T\&D frequency, performance appraisals, feedback, incentive schemes, pay level and non-monetary rewards, and HR planning techniques. An example item is "To get my job here, I needed to take an interview". A five-point Likert scale was used to assess each item $(1=$ strongly disagree, $5=$ strongly agree $)$. In order to avoid multi-collinearity and to identify the underlying clusters of practices, factor analysis was performed prior to multiple regression analysis (Field, 2013). By adopting the criterion of eigenvalues $(>1)$ and considering the scree plot, five factors were retained, explaining $52.4 \%$ of variance in total. After rotation and examination of items' loadings on factors, these factors reflect five clusters of HRM practices by function, they are, staffing, training and development (T\&D), performance management (PM), reward management (RM) and HR planning (HRP) practices respectively. The Cronbach's $\alpha$ reliability coefficients of the sub-scales were 0.84 (staffing), 0.91 (T\&D), 0.76 (PM), 0.86 (RM), and 0.82 (HRP). 
$\mathrm{AC}, \mathrm{CC}$ and $\mathrm{NC}$ were measured by three items for each using a five-point Likert scale $(1=$ strongly disagree, $5=$ strongly agree $)$. An abridged version of the scale developed by Meyer et al. (1993) was adopted. The scores of these individual variables were taken as the average of scores of three items. An example item for AC is: "I would be very happy to spend the rest of my career with this organisation". Nazir et al. (2016, p. 605) note that Meyer et al.'s (1993) commitment scale has been: “... extensively used in numerous geographical and organizational context, including those involving Chinese subordinates ... and has been well accepted for representing high reliability and validity". The reliability coefficients of sub-scales of $\mathrm{AC}, \mathrm{CC}$ and $\mathrm{NC}$ were $0.83,0.60$ and 0.79 respectively provide further support for Nazir et al.'s (2016) assertion though, in order to maintain confidence in the reliability of the findings, the $\mathrm{CC}$ variable was not included in the following analysis and Hypothesis $1 \mathrm{~b}$ was not tested.

Turnover intention was measured by three items (Cronbach's $\alpha=0.94)$ reflecting the first to third mental stages of turnover identified by Mobley et al. (1978). An example item is "I am thinking about quitting my current job in the near future". A five-point Likert scale was applied with response categories ranging from 1 (strongly disagree) to 5 (strongly agree).

Firm size, length of service, rank, and gender were controlled for the prediction of employee outcomes since it has been suggested that these variables may exert a potential impact on OC and TI (Kuvaas, 2008; Zheng et al., 2006). In this study, size is the number of full-time employees hired by organisation. Rank indicates whether a respondent is managerial or non-managerial staff. Dummy variables were created for gender and rank.

As the data are cross-sectional and self-reported, common method variance (CMV) may be a potential threat to the interpretations of relationships among variables 
(Podsakoff et al., 2003). Thus, some actions were taken to minimise common method bias such as emphasising to respondents that their responses would be anonymised and also the need for them to respond honestly; these actions have been highlighted as procedural remedies to reduce respondents' evaluation apprehension (ibid, 2003). Further, the widely employed statistical technique, Harman's single-factor test, was also conducted to diagnose potential bias. The result shows that more than one factor was extracted and no general factor accounted for the majority of the variance, indicating CMV is unlikely to be a problem in the current study (ibid, 2003).

\section{Results}

Table 1 reports descriptive statistics and Pearson product-moment correlations among variables. The results showed that $\mathrm{AC}, \mathrm{NC}$ and $\mathrm{TI}$ were significantly related to employees' perceptions of all HRM practices, indicating the predictions of this study are supported. In addition, rank showed significant correlations with all employee outcome variables and T\&D and HRP practices. Size had significant relationship with staffing practices but not with others. Gender and length of service showed no statistically significant correlations with other variables.

[Take in table 1 here]

To test the research hypotheses, multiple regressions were performed. The results are outlined in Table 2. The analyses showed that all three models had statistically significant predictive power, suggesting all five groups of employees' perceptions of HRM practices were significant predictors $(p<0.01)$ for AC, NC and TI, thus supporting Hypothesis 1a, $1 \mathrm{c}$ and 2 . The tolerance values were greater than 0.1 and VIF values were 
less than 10, indicating multicollinearity was not a concern for the models (Orme and Combs-Orme, 2009). The adjusted $R^{2}$ values indicated that $65.3 \%$ of the variation in AC, $58.7 \%$ of the variation in $\mathrm{NC}$ and $60.7 \%$ of the variation in $\mathrm{TI}$ were explained by the five groups of HRM practices. It is reasonable to say that employees' perceptions of HRM practices adequately explain the variation in three employee outcome variables.

[Take in table 2 here]

Regarding to the predictive strengths of independent variables, the regression analyses further suggested that T\&D (AC: $\beta=.484, p<.001 ; \mathrm{NC}: \beta=.471, p<.001$; TI: $\beta=-.469, p<.001)$ and RM practices (AC: $\beta=.371, p<.001 ; \mathrm{NC}: \beta=.335, p<.001$; TI: $\beta=-.336, p<.001)$ were the most important predictors for $\mathrm{AC}, \mathrm{NC}$ and $\mathrm{TI}$ in the models. PM practices (AC: $\beta=.186, p<.001$; NC: $\beta=.167, p<.001$ ) had the weakest strength for AC and NC. As for TI, staffing practices $(\beta=-.196, p<.001)$ were the weakest. All control variables showed non-significant effects with all $p$ values of T tests greater than 0.05 .

In summary, the results support the research hypotheses: the greater the perceived use of HRM practices, the higher level of employees' affective commitment and normative commitment, but the lower level of their turnover intention.

\section{Discussion-and conclusions}

This study examines how employees' perceptions of HRM practices impact on employee outcomes in Chinese privately-owned SMEs. The findings reveal that employees' perceptions of all five groups of HRM practices including staffing, T\&D, PM, RM and $\mathrm{HRP}$ are significant predictors of $\mathrm{AC}, \mathrm{NC}$, providing a strong indication that the perceived 
use of sophisticated HRM practices increases employees' AC and NC. These results are partially in line with Meyer and Smith (2000)'s findings based on small firms in Canada, which suggested AC and NC were predicted by career development, benefits and performance appraisal practices but not by training practices. The findings are also partially consistent with Chew and Chan (2008) who found a positive relationship between OC and compensation, but a non-significant association with training and career development in large Australian firms. The inconsistency could be due to size, sector, and national differences, though size shows a non-significant effect in the current study. In the Chinese context, similar results were obtained by Zheng et al. (2009), who argued that the adoption of innovative HRM practices had positive effects on commitment. This study also compared and revealed the varying strengths of five clusters of HRM practices, suggesting employees' perceptions of T\&D and RM practices are likely to have a stronger relationship with employee commitment than others.

Another key finding indicates that employee TI can be reduced by greater perceived use of the five groups of HRM practices in the SME sector. This finding is in line with previous studies which suggested a negative direct/indirect relationship between TI and actual/perception of HRM practices, especially between TI and compensation practices (Chew and Chan, 2008; Dhiman and Mohanty, 2010; Juhdi et al., 2013). The results further show that employees' perceptions of T\&D practices have the strongest relationship with $\mathrm{TI}$, followed by RM practices and others. Interestingly, this finding contrasts with Juhdi et al. (2013) who suggested T\&D-related practices are not a significant predictor of TI, but supports Chew and Chan (2008) and Kuvaas (2008) who found a significant effect. A possible explanation for the contrasting findings might be the different nature of the organisations in the various samples and varying contextual factors. 
The vulnerable nature of SMEs in China, the widespread labour shortage and structural conflict in Chinese labour market is noted above. As such, SMEs in China, especially those which are privately-owned, are often likely to struggle with limited budgets, employee commitment and the retention of a well-motivated and highly qualified workforce. The findings of this study provide some evidence that employees' perceptions relating to the application of HRM may offer a positive contribution to providing an effective approach to these problems. The findings have indicated that all of the HRM practices under scrutiny were positively related to employee commitment and reducing turnover intention. Given that the findings are based on the self-reported perceptions of employees, they emphasise the importance that SMEs should place on not only adopting and using the HRM practices in question but also communicating this use to their employees.

Researchers have pointed out that HRM systems achieve better outcomes when different HRM practices are effectively integrated (Guest, 2001). Nevertheless, it should be highlighted that SMEs may not have sufficient resources to implement a complete bundle of practices. Thus, it may be necessary to prioritise those practices in order of importance. Our findings emphasise the relative importance of how employees perceive training and development activities in SMEs. However, earlier evidence shows that SMEs are unlikely to take T\&D into account due to factors such as associated costs, long-term orientation, possible job hopping of well-trained employees and unperceived skill shortages by employers (Cunningham, 2010; Richbell et al., 2010). In essence, the perceived benefits of T\&D may not be given due value in the short term by, for example, owners of SMEs. Yet, on the basis of our findings, T\&D should be seen as a particularly useful activity for SMEs to engage in and internally market, not only to build competence, but also to increase commitment and retain employees. 
Another key HR function in SMEs tends to be reward management. The positive impact of RM on commitment and turnover intention has been widely supported by previous research (Chew and Chan, 2008; Juhdi et al., 2013; Nazir et al., 2016). This is not surprising as compensation appears to be a key issue to employees in the SME sector. The reason might be related to SMEs' informal nature; in another words, their reputation, prospects for development, personal T\&D opportunities and job security are hardly comparable to those in large firms. For example, in their study of $\mathrm{N}=195$ SMEs based in Pakistan, Khan and Khan's (2012) found that compensation-related practices were considered by owners/managers as the most crucial part of HRM activities. The expectation of people working in SMEs may tend to focus on compensation rather than other aspects of the employment relationship. The findings of the current study indicate that increases in the perceived use of RM practices may help to contribute to improving employee outcomes with reference to OC and TI among employees of SMEs based in China.

At a more theoretical level, the findings of the current study provide strong support and add empirical evidence to the theoretical propositions underpinning the Harvard Framework. By revealing the relationship between employees' perceptions of HRM practices and HR outcomes, the findings demonstrate the importance and value of employing and, importantly, publicising the use of, formal HRM practices specifically in SMEs in China. The findings also echo the RBV by highlighting that affective aspects of the SMEs' workforce capacity can be enhanced by means of effective HRM practices. In addition, the current research provides a set of scales with conventionally acceptable reliability to measure HRM practices in the SME sector which could be used as a reference for future SME studies. 
Hypothesis $1 \mathrm{~b}$ was not tested because of the low reliability of $\mathrm{CC}$ sub-scale (Cronbach's $\alpha<0.7)$. The adopted sub-scale of CC seems to be problematic and not readily applicable to a Chinese sample. Such a result is consistent with prior studies in the Asian context, which suggested the reliability of $\mathrm{CC}$ data was relatively low while that of AC was relatively high (Cheng and Stockdale, 2003). Although Meyer and Allen's (1991) OC model and its measurement scales are well-established and widely employed in different settings, the findings of this paper provide evidence that the applicability and transferability of the model are likely to differ in Chinese contexts. In particular, measures of $\mathrm{AC}$ and $\mathrm{NC}$ are likely to transfer to Chinese cultural settings while data collection of $\mathrm{CC}$ using fixed response questionnaire scales may be more problematic. There could be two possible explanations. One is whether $\mathrm{CC}$ is commonly understood as a necessary component of OC; the other is how the CC concept is interpreted in the Chinese contexts. It would be interesting for future studies to explore if these three components are interpreted differently in western and Asian contexts and, if so, why.

\section{$\underline{\text { Conclusion }}$}

Overall, this paper extends knowledge about the effects of HRM practices in SMEs in China. It makes a contribution by helping to address the dearth of studies which have explored the effectiveness of HRM in this context by involving SMEs in both eastern and western China. Unlike more mainstream studies, the present study highlights that there is a relationship between employees' perceptions about the use of HRM practices and employee outcomes at the individual level. The findings are useful for SME owners and HR practitioners. This relationship between employees' perceptions of the use of HRM practices and employee outcomes in Chinese SMEs can be applied as a mechanism for generating desirable employee attitudes and behaviours, which, ultimately are likely to improve organisational performance. The findings also provide robust justification for 
attaching importance to implementing HRM in SMEs. The varying strengths of the five groups of HRM practices explored in this study could be used by resource-constrained SMEs to help inform HRM choices and optimise resource allocation.

Four important limitations of this research need to be acknowledged. First, the study examined five main groups of HRM practices; it is not claimed that these practices represent HRM in its entirety. Others HRM practices, linked more directly to topics such as work-life balance and the employment relationship could be investigated in future studies. Second, the methodology relies on self-report attitudinal scales relating to employees' perceptions about the use of HR practices by their employers; while valuable in their own right, the extent to which these perceptions are shared by SME owners and are reflective of actual HRM practices within the SME merits further research. Third, the study is not designed to determine issues of causality relating to the employees' perceptions of HR practices and employee outcomes such as turnover and commitment. For example, it may be hypothesised that relatively high levels of commitment may lead employees to hold relatively positive perceptions of HRM practices or, alternatively, employees' relatively positive perceptions of HRM practices may lead to relatively high levels of commitment. Fourth, the data were collected from two provinces and this may limit the generalisability of the findings (Sheldon and Sanders, 2016). While these two provinces tend to be representative of eastern and western China, future research could involve a larger number of SMEs drawn from more regions in China.

\section{References}

Bai, Y., Yuan, J. and Pan, J. (2017), "Why SMEs in emerging economies are reluctant to provide employee training: evidence from China", International Small Business Journal: Researching Entrepreneurship, Vol. 35 No. 6, pp. 751-766. 
Beer, M., Spector, B., Lawrence, P.R., Mills, D.O. and Walton, R.E. (1984), Managing Human Assets, Free Press, New York.

Bowen, D. E., and Ostroff, C. (2004), "Understanding HRM-firm performance linkages: the role of the "strength" of the HRM system", Academy of Management Review, Vol 29, pp. 203-221

Boxall, P. and Purcell, J. (2011), Strategy and Human Resource Management, 3rd ed., Palgrave Macmillan, Basingstoke.

Cafferkey, K., Heffernan, M., Harney, B., Dundon, T. and Townsend, K. (2018, "Perceptions of HRM system strength and affective commitment: the role of human relations and internal process climate", International Journal of Human Resource Management, DOI: 10.1080/09585192.2018.1448295 [accessed $12^{\text {th }}$ November 2018]

Cai, Z., Morris, J.L. and Chen, J. (2011), "Explaining the human resource management preferences of employees: a study of Chinese workers", The International Journal of Human Resource Management, Vol. 22 No. 16, pp. 3245-3269.

Cegarra-Leiva, D., Sánchez-Vidal, M.E. and Cegarra-Navarro, J.G. (2012), "Work life balance and the retention of managers in Spanish SMEs", The International Journal of Human Resource Management, Vol. 23 No. 1, pp. 91-108.

Ceylan, C. (2013), “Commitment-based HR practices, different types of innovation activities and firm innovation performance", The International Journal of Human Resource Management, Vol. 24 No. 1, pp. 208-226.

Cheng, Y. and Stockdale, M.S. (2003), "The validity of the three-component model of organisational commitment in a Chinese context", Journal of Vocational Behavior, Vol. 62 No. 3, pp. 465-489.

Chew, J. and Chan, C.C.A. (2008), "Human resource practices, organisational commitment and intention to stay", International Journal of Manpower, Vol. 29 No. 6, pp. 503-522.

Chowhan, J. (2016), "Unpacking the black box: understanding the relationship between strategy, HRM practices, innovation and organizational performance", Human Resource Management Journal, Vol. 26 No. 2, pp. 112-133.

Cooke, F.L. (2005), "Employment relations in small commercial businesses in China", Industrial Relations Journal, Vol. 36 No. 1, pp. 19-37. 
Cooke, F.L. (2009), “A decade of transformation of HRM in China: a review of literature and suggestions for future studies", Asia Pacific Journal of Human Resources, Vol. 47 No. 1, pp. 6-40.

Cooke, F.L. (2012), Human Resource Management in China: New Trends and Practices, Routledge, Abingdon.

Cunningham, L.X. (2010), "Managing human resources in SMEs in a transition economy: evidence from China", The International Journal of Human Resource Management, Vol. 21 No. 12, pp. 2120-2141.

Cunningham, L.X. (2011), "SMEs as motor of growth: a review of China's SMEs development in thirty years (1978-2008)", Human Systems Management, Vol. 30 No. 1-2, pp. 39-54.

Cunningham, L.X. and Rowley, C. (2008), "The development of Chinese small and medium enterprises and human resource management: a review", Asia Pacific Journal of Human Resources, Vol. 46 No. 3, pp. 353-379.

Cunningham, L.X. and Rowley, C. (2010), "Small and medium-sized enterprises in China: a literature review, human resource management and suggestions for further research”, Asia Pacific Business Review, Vol. 16 No. 3, pp. 319-337.

Dhiman, G.R. and Mohanty, R.P. (2010), "HRM practices, attitudinal outcomes and turnover intent: an empirical study in Indian oil and gas exploration and production sector", South Asian Journal of Management, Vol. 17 No. 4, pp. 74104.

Eisinga, R., Teelken, C. and Doorewaard, H. (2010), “Assessing cross-national invariance of the three-component model of organisational commitment: a sixcountry study of European university faculty", Cross-Cultural Research, Vol. 44 No. 4, pp. 341-373.

Eriksson, T., Qin, Z. and Wang, W. (2014), "Firm-level innovation activity, employee turnover and HRM practices - evidence from Chinese firms", China Economic Review, Vol. 30 September, pp. 583-597.

Fabi, B., Lacoursière, R. and Raymond, L. (2015), "Impact of high-performance work systems on job satisfaction, organizational commitment, and intention to quit in Canadian organizations", International Journal of Manpower, Vol. 36 No. 5, pp. 772-790.

Field, A. (2013), Discovering Statistics Using IBM SPSS Statistics, 4th ed., Sage, London. 
Gould-Williams, J. and Mohamed, R.B. (2010), "A comparative study of the effects of 'best practice' HRM on worker outcomes in Malaysia and England local government", The International Journal of Human Resource Management, Vol. 21 No. 5, pp. 653-675.

Guest, D.E. (2001), "Human resource management: when research confronts theory”, The International Journal of Human Resource Management, Vol. 12 No. 7, pp. 10921106.

Hailey, V.H., Farndale, E. and Truss, C. (2005), "The HR department's role in organisational performance", Human Resource Management Journal, Vol. 15 No. 3, pp. 49-66.

Harney, B., and Dundon, T. (2006) "Capturing complexity: developing an integrated approach to analysing HRM in SMEs", Human Resource Management Journal, Vol. 16 No. 1, pp. 48-73.

Hu, E., Zhang, M., Shan, H., Zhang, L. and Yue, Y. (2018), "Job satisfaction and union participation in China: Developing and testing a mediated moderation model", Employee Relations, Vol. 40 Issue: 6, pp.964-980

Juhdi, N., Pa'wan, F. and Hansaram, R.M.K. (2013), "HR practices and turnover intention: the mediating roles of organizational commitment and organizational engagement in a selected region in Malaysia", The International Journal of Human Resource Management, Vol. 24 No. 15, pp. 3002-3019.

Katou, A.A. and Budhwar, P.S. (2007), "The effect of human resource management policies on organizational performance in Greek manufacturing firms", Thunderbird International Business Review, Vol. 49 No. 1, pp. 1-35.

Kehoe, R.R. and Wright, P.M. (2013), "The impact of high-performance human resource practices on employees' attitudes and behaviors", Journal of Management, Vol. 39 No. 2, pp. 366-391.

Khan, N.R. and Khan, M.R. (2012), "Human resource practices in SME sector: an exploratory case study of Pakistan”, Euro Economica, Vol. 3 No. 31, pp. 7-19.

Kim, N. (2014), "Employee turnover intention among newcomers in travel industry”, International Journal of Tourism Research, Vol. 16 No. 1, pp. 56-64. 
Kim, Y. and Gao, F.Y. (2010), "An empirical study of human resource management practices in family firms in China", The International Journal of Human Resource Management, Vol. 21 No. 12, pp. 2095-2119.

Krishnan, T. N., and Scullion, H. (2017), “Talent management and dynamic view of talent in small and medium enterprises", Human Resource Management Review, Vol. 27 No. 3, pp. 431-441

Kotey, B. and Slade, P. (2005), "Formal human resource management practices in small growing firms", Journal of Small Business Management, Vol. 43 No. 1, pp. 1640.

Kuean, W.L., Kaur, S. and Wong, E.S.K. (2010), “The relationship between organizational commitment and intention to quit: the Malaysian companies perspectives", Journal of Applied Sciences, Vol. 10 No. 19, pp. 2251-2260.

Kuvaas, B. (2008), "An exploration of how the employee-organization relationship affects the linkage between perception of developmental human resource practices and employee outcomes", Journal of Management Studies, Vol. 45 No. 1, pp. 1-25.

Lai, Y., Saridakis, G. and Johnstone, S. (2017), "Human resource practices, employee attitudes and small firm performance", International Small Business Journal, Vol. 35 No. 4, pp. 470-494.

Lambert, E. and Hogan, N. (2009), “The importance of job satisfaction and organizational commitment in shaping turnover intent: a test of a causal model", Criminal Justice Review, Vol. 34 No. 1, pp. 96-118.

Lee, F.H., Lee, T.Z. and Wu, W.Y. (2010), “The relationship between human resource management practices, business strategy and firm performance: evidence from steel industry in Taiwan", The International Journal of Human Resource Management, Vol. 21 No. 9, pp. 1351-1372.

Maksimov, V., Wang, S.L. and Luo, Y. (2017), "Reducing poverty in the least developed countries: the role of small and medium enterprises", Journal of World Business, Vol. 52 No. 2, pp. 244-257.

Marchington, M. (2015), "Human resource management (HRM): too busy looking up to see where it is going longer term?" Human Resource Management Review, Vol. 25 No. 2, pp. 176-187. 
Meyer, J.P. and Allen, N.J. (1991), "A three-component conceptualization of organizational commitment", Human Resource Management Review, Vol. 1 No. 1, pp. 61-89.

Meyer, J.P., Allen, N.J. and Smith, C.A. (1993), "Commitment to organizations and occupations: extension and test of a three-component conceptualization", Journal of Applied Psychology, Vol. 78 No. 4, pp. 538-551.

Meyer, J.P. and Smith, C.A. (2000), "HRM practices and organizational commitment: test of a mediation model", Canadian Journal of Administrative Sciences, Vol. 17 No. 4, pp. 319-331.

Mobley, W.H., Horner, S.O. and Hollingsworth, A.T. (1978), "An evaluation of precursors of hospital employee turnover", Journal of Applied Psychology, Vol. 63 No. 4, pp. 408-414.

Nazir, S., Shafi, A., Qun, W., Nazir, N. and Tran, Q.D. (2016), "Influence of organizational rewards on organizational commitment and turnover intentions", Employee Relations, Vol. 38 No 4, pp. 596-619.

Newman, A. and Sheikh, A. (2012), "Organizational rewards and employee commitment: a Chinese study”, Journal of Managerial Psychology, Vol. 27 No. 1, pp.71-89.

Nishii, L. H., Lepak, D. P., and Schneider, B. (2008), "Employee attributions of the "why" of HR practices: their effects on employee attitudes and behaviors, and customer satisfaction", Personnel Psychology, Vol 61, No. 3, pp. 503-545.

Orme, J.G. and Combs-Orme, T. (2009), Multiple Regression with Discrete Dependent Variables, Oxford University Press, New York.

Pajo, K., Coetzer, A. and Guenole, N. (2010), "Formal development opportunities and withdrawal behaviors by employees in small and medium-sized enterprises", Journal of Small Business Management, Vol. 48 No. 3, pp. 281-301.

People's Republic of China (PRC) (2004), “The Constitution of PRC”, available at: www.gov.cn/gongbao/content/2004/content_62714.htm (accessed 5 September 2017).

People's Republic of China (PRC) (2011), "Provisions on the standards for SMEs", available at: www.gov.cn/zwgk/2011-07/04/content_1898747.htm (accessed 9th September 2017). 
Pittino, D., Visintin, F., Lenger, T. and Sternad, D. (2016), “Are high performance work practices really necessary in family SMEs? An analysis of the impact on employee retention", Journal of Family Business Strategy, Vol. 7 No. 2, pp. 75-89.

Podsakoff, P.M., MacKenzie, S.B., Lee, J. and Podsakoff, N.P. (2003), “Common method biases in behavioral research: a critical review of the literature and recommended remedies", Journal of Applied Psychology, Vol. 88 No. 5, pp. 879-903.

Qiao, K., Wang, X. and Wei, L. (2015), "Determinants of high performance work systems in small and medium sized enterprises in China", Asia Pacific Journal of Human Resources, Vol. 53 No. 2, pp. 185-203.

Richbell, S., Szerb, L. and Vitai, Z. (2010), "HRM in the Hungarian SME sector", Employee Relations, Vol. 32 No. 3, pp. 262-280.

Saridakis, G., Lai, Y. and Copper, C.L. (2017), "Exploring the relationship between HRM and firm performance: a meta-analysis of longitudinal studies", Human Resource Management Review, Vol. 27 No. 1, pp. 87-96.

Saridakis, G., Muñoz Torres, R. and Johnston, S. (2013), "Do human resource practices enhance organizational commitment in SMEs with low employee satisfaction?", British Journal of Management, Vol. 24 No. 3, pp. 445-458.

Shen, J. and Leggett, C. (2014) "The effects of hukou (official household residential status) on perceived human resource management practices and organizational justice in China", Personnel Review, Vol. 43 Issue: 2, pp.168183

Sheldon, P. and Sanders, K. (2016), “Contextualising HRM in China: differences within the country", The International Journal of Human Resource Management, Vol. 27 No. 18, pp. 2017-2033.

Storey, D.J., Saridakis, G., Sen Gupta, S., Edwards, P.K. and Blackburn, R.A. (2010, "Linking HR formality with employee job quality: the role of firm and workplace size” Human Resource Management, Vol. 49 No.2, pp. 305-329

Sun, R. and Wang, W. (2017), "Transformational leadership, employee turnover intention, and actual voluntary turnover in public organizations", Public Management Review, Vol. 19 No. 8, pp. 1124-1141

Wang, K. (2016), “Labour resistance and worker attitudes towards trade union reform in China”-", Employee Relations, Vol. 38 Issue: 5, pp.724-740 
Warner, M. (2009), “-Making sense' of HRM in China: setting the scene”, The International Journal of Human Resource Management, Vol. 20 No. 11, pp. 2169-2193.

Warner, M. (2011), "Labour markets in China: coming to terms with globalization”, in Benson, J. and Zhu, Y. (Eds.), The Dynamics of Asian Labour Markets: Balancing Control and Flexibility, Routledge, Abingdon, pp. 134-147.

Wright, P.M., Gardner, T.M., Moynihan, L.M. and Allen, M.R. (2005), “The relationship between HR practices and firm performance: examining causal order", Personnel Psychology, Vol. 58 No. 2, pp. 409-446.

Wright, P.M., McMahan, G.C. and McWilliams, A. (1994), "Human resource and sustained competitive advantage: a resource-based perspective", The International Journal of Human Resource Management, Vol. 5 No. 2, pp. 301326.

Zheng, C., Morrison, M. and O’Neill, G. (2006), “An empirical study of high performance HRM practices in Chinese SMEs", The International Journal of Human Resource Management, Vol. 17 No. 10, pp. 1772-1803.

Zheng, C., Morrison, M. and O’Neill, G. (2009), “Enhancing Chinese SME performance through innovative HR practices”, Personnel Rfeview, Vol. 38 No. 2, pp. 175194. 
Table 1. Descriptive statistics and Pearson product-moment correlations among variables.

\begin{tabular}{|c|c|c|c|c|c|c|c|c|c|c|c|c|}
\hline & 1 & 2 & 3 & 4 & 5 & 6 & 7 & 8 & 9 & 10 & 11 & 12 \\
\hline 1. Size & 1 & & & & & & & & & & & \\
\hline 2. Gender & -.044 & 1 & & & & & & & & & & \\
\hline 3. Service length & .120 & .070 & 1 & & & & & & & & & \\
\hline 4. Rank & .024 & .060 & $-.346^{* *}$ & 1 & & & & & & & & \\
\hline 5. T\&D & -.105 & -.014 & .094 & $-.314^{* *}$ & 1 & & & & & & & \\
\hline 6. $\mathrm{RM}$ & .002 & -.068 & -.013 & -.095 & .092 & 1 & & & & & & \\
\hline 7. Staffing & $.342^{* *}$ & -.059 & -.034 & -.046 & .067 & .052 & 1 & & & & & \\
\hline 8. PM & -.013 & -.013 & -.042 & -.001 & .037 & .050 & .072 & 1 & & & & \\
\hline 9. HRP & .040 & -.107 & .025 & $-.171^{* *}$ & .090 & .003 & .022 & .025 & 1 & & & \\
\hline 10. $\mathrm{AC}$ & .083 & -.035 & -.017 & $-.252^{* *}$ & $.565^{* *}$ & $.441^{* *}$ & $.353^{* *}$ & $.250^{* *}$ & $.307^{* *}$ & 1 & & \\
\hline 11. NC & -.019 & -.047 & .029 & $-.300^{* *}$ & $.574^{* *}$ & $.409^{* *}$ & $.327^{* *}$ & $.228^{* *}$ & $.236^{* *}$ & $.791^{* *}$ & 1 & \\
\hline 12. TI & .020 & .067 & .035 & $.250^{* *}$ & $-.556^{* *}$ & $-.405^{* *}$ & $-.258^{* *}$ & $-.275^{* *}$ & $-.352^{* *}$ & $-.829^{* *}$ & $-.730^{* *}$ & 1 \\
\hline Mean & 100.62 & .533 & 31.30 & .727 & .000 & .000 & .000 & .000 & .000 & 3.629 & 3.427 & 2.797 \\
\hline SD & 99.498 & .50 & 30.322 & .447 & .908 & .882 & .877 & .886 & .896 & .775 & .765 & .901 \\
\hline
\end{tabular}

Notes: **. Correlation is significant at the 0.01 level (2-tailed). $N=227$.

Gender $($ male $=0$; female $=1)$; Rank (managerial staff $=0$; non-managerial staff $=1)$. 
Table 2. Results of multiple regression on three employee outcomes.

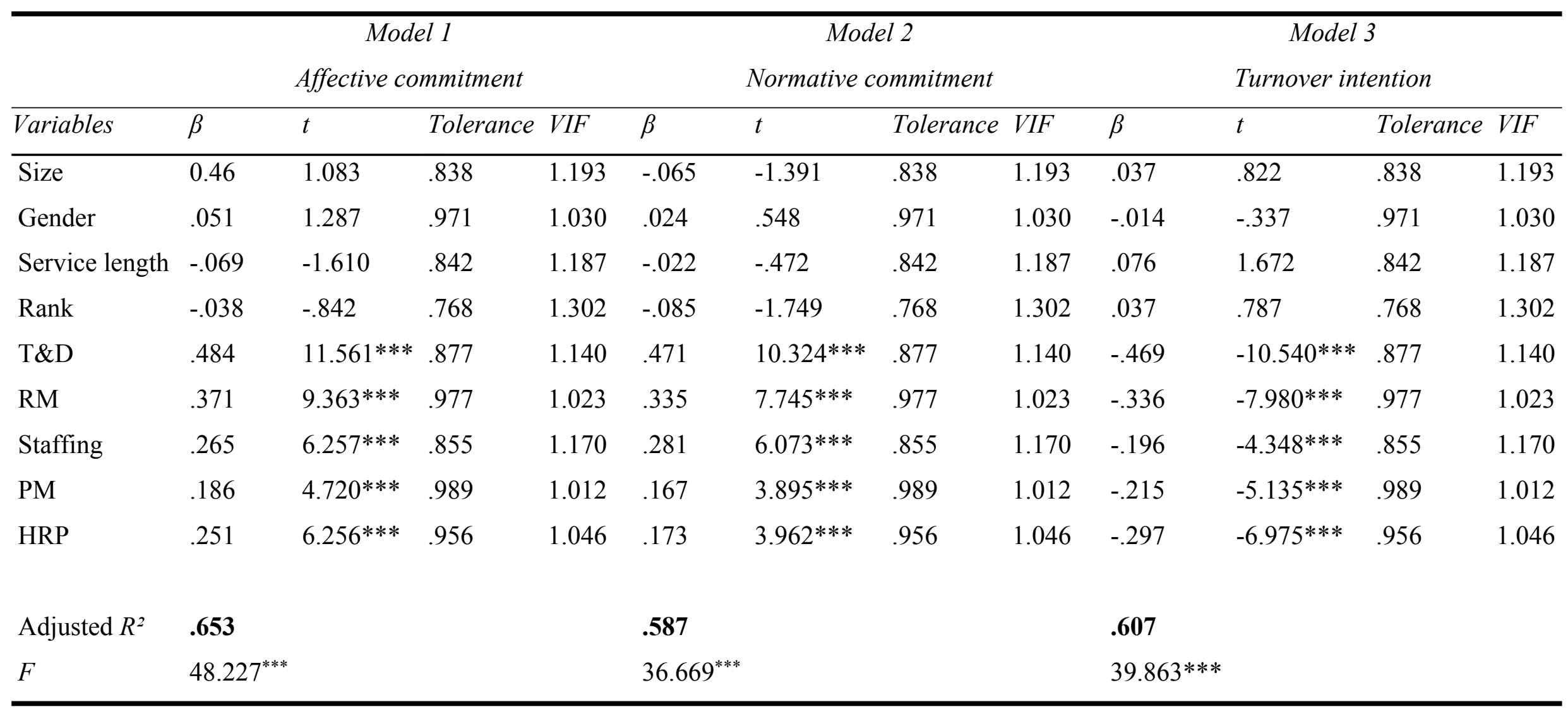

Notes: Standardised $\beta$ coefficients are reported. ${ }^{*} p<0.05 ; * * p<0.01 ; * * * p<0.001$.

Gender $($ male $=0 ;$ female $=1)$; Rank $($ managerial staff $=0$; non-managerial staff $=1)$. 